\title{
CHANGES IN THE LABOUR MARKET IN THE REGIONS OF SLOVAKIA
}

\author{
Dana JAŠKOVÁ
}

\begin{abstract}
Workforce requirements change under the influence of changes in the achieved level of human knowledge in the organization of work and work procedures. These changes are constantly taking place, differing in nature and pace. At present, the rapid pace of these changes is characteristic. This is caused by automation, digitization, and robotics, which penetrate all spheres of society. Knowing the changes in the labour market in regions, is important for the development of society. The aim of the paper is to comprehensively evaluate changes in the labor market in the regions of Slovakia, using multidimensional statistical methods.
\end{abstract}

Key words:

labour market, labour market indicators, Composite Indicator, multivariate statistical methods

JEL Classification: L63, J21, R11

DOI: https://doi.org/10.52665/ser20210102

\section{Introduction}

New technologies and a more integrated, globalized world offer many opportunities for creating new jobs, improving the quality of existing jobs, and bringing previously underrepresented groups into the labour market. Both technological change and globalization create jobs by lowering the price of goods and services, increasing their quality and, hence, boosting consumer demand. The quality of jobs can be improved: dangerous or boring tasks can be automated; people can choose where and when to work more freely, resulting in a better work-life balance; work environments can be made safer and healthier. By breaking down traditional barriers to labour market participation, previously underrepresented groups can increasingly participate in the labour market, resulting in greater inclusiveness.

According to Neufeind et al. (2018) workforce requirements change due to changes in the achieved level of human knowledge in the organization of work and work procedures. These changes are constantly taking place, differing in nature and pace. Currently, this pace is very fast. This is caused by automation, digitization, and robotics, which penetrate all spheres of society. Knowing the impact of these processes, called Industry 4.0, is important for the development of society.

The industry 4.0 becomes in 21 st century one of the major trends with global impact. It is known as a boom (increase of production and circulation of global economy), the economic forces in the world are crossing borders (Havierniková and Král'ová, 2018). The Industry 4.0 concept has been gradually adopted by organizations in several countries around the world. This has brought new challenges. These challenges relate to the skill level of the workforce. Skills that are currently preferred in the labor market are likely to lose their priority in the future. A higher percentage of jobs will emphasize cognitive skills. There is currently a debate about job losses in the future. Many experts believe that the adoption of Industry 4.0 will lead to increased use of automation and robots in manufacturing (Schwab, 2015).

The speed and measure of the changes coming about by the fourth industrial revolution are not to be ignored. These changes will bring about shifts in power, shifts in wealth, and 
knowledge. Only in being knowledgeable about these changes and the speed in which this is occurring can we ensure that advances in knowledge and technology reach all and benefit all (Xu et al.,2018).

Digitization offers the potential for quality improvement, flexibility, and productivity (Hoellthaler et al., 2018). The intention of using the processes of informatization and cybernetization is the development of society, not its threat. It can be assumed that the use of new technologies will not result in job losses. On the contrary, increased labor productivity and product quality. One of the topics is the expected impact on employment (Vuksannovič et al., 2016). The system of work-related skills required outweighs physical abilities. Apparently, some low-skilled jobs will be lost. Increasing capacity will have a positive effect on job creation, which requires a higher level of skills (Berger, 2016).

All the described processes affect the changes in the labour market. Due to regional disparities in Slovakia, it is possible to anticipate various shifts in the labour market in these regions. The aim of the paper is to comprehensively assess changes in the labour market in the regions of Slovakia.

\section{GOAL AND METHODOLOGY}

Multidimensional statistical methods were used to assess changes in the labour market in the regions of Slovakia. For the character of the labour market, 12 indicators were selected from the official database of the Statistical office of SR (DataCube, 2021). The suitability of the indicators was assessed according to the recommendations of the International Labor Office (ILO) organization. ILO launched the Key Indicators of the Labour Market (KILM) (ILO, 2016). The KILM was originally designed with two primary objectives in mind. First to present a core set of labour market indicators and second to improve the availability of the indicators to monitor new employment trends. The selection of the indicators was based on some criteria. Conceptual relevance, data availability and relative comparability across countries and regions.

The Key indicators of the labour market is a collection of $17 \mathrm{key}$ indicators of the labour market; covering employment and other variables relating to employment (status, economic activity, occupation, hours of work etc.), employment in the informal economy, unemployment and the characteristics of the unemployed, underemployment, education, wages and compensation costs, labour productivity and working poverty. KILM is based on data from ILOSTAT (the ILO consolidated database), augmented by data from other international repositories and with estimates and projections carried out by the ILO Research Department and Department of Statistics. A key aim of the KILM is to present a core set of labour market indicators in a userfriendly manner.

To compare regions in terms of labour market, this phenomenon must be quantified. At present, the methodology of constructing an aggregated indicator, which is called a Composite Indicator $(C I)$, is preferred. The OECD published a detailed methodology for its construction. The OECD's Handbook on Constructing Composite Indicators (Nardo et al., 2005) describes different methodologies that can be applied to combine varied information into this index and the difficulties associated with each part of the process. A composite indicator is an indicator that is constructed from several indicators and evaluates the region from different perspectives. The composite indicator should allow a more comprehensive, coherent, and synthesizing view of the level of the region (Minařík, 2013).

The evaluation of the labour market of the region is diverse, considering the purpose pursued, the choice of method and its correct application. The selection of indicators for their evaluation is also important. A key role is played by the way they are integrated into a single indicator and the subsequent correct interpretation of the results. The indicator must 
be significant, relevant, understandable, transparent, analytical, complete, internally comparable, and externally comparable. These requirements must be respected in their selection.

The construction of CI can be described by the following steps: creation of a theoretical framework, selection and combination of input indicators, assessment of their material significance, statistical characteristics, weighting, normalization, aggregation, relation to input indicators, visualization of results. Summary indicators have both advantages and disadvantages. They are discussed in detail by Saisana and Tarantola (2002).

\section{Methods of construction of summary indicator}

Methods of construction of the aggregate indicator can be divided into statisticalanalytical methods, which are focused on the selection of input indicators and statisticaldescriptive methods, which allow calculation of the aggregate indicator.

One-dimensional statistical methods provide an overview of the analyzed indicators. Multidimensional methods are used in the construction of composite indicators to find the optimal number of input indicators, reduce them, and reveal the similarity of the examined objects (cluster analysis, correlation analysis and analysis of main components). The statistical-descriptive methods allow the computation of the aggregate indicator using aggregation techniques and the analyticalhierarchical process, which is based on different ways of determining weights for individual indicators in their aggregation.

Throughout this section, we will use the following designation: $y_{i, t}^{r}$ - the original value of the indicator $i$, of the region $r$ in year $t$ (2010; 2019), where $i=1, \ldots, 12, \quad I_{i, t^{-}}^{r}$ normalized indicator value $y_{i, t}^{r}$ in year $t, w_{i}$ weight associated with indicator $i, \mathrm{CI}_{t}^{r}$ value of composite indicator over time $t$. The following methods can be used to normalize input indicators: Normalization based on interval scales, Standardization z-scores, Min-Max,
Distance to a reference, Methods for cyclical indicators and Percentage of annual differences over consecutive years. The weight of the indicator can be determined by subjective methods, expert decision, and Point method. Objective methods include methods: Equal weighting (EW), Principal component analysis (PCA), Benefit of the doubt (BOD), Unobserved components models (UCM), Budget allocation process (BAP), Analytic hierarchy process (AHP), Conjoint analysis (CA.)

\section{Expected changes in the labour market in the Slovak Republic}

The recalculations made on job losses and creation differ with the methodology used. Approximate official recalculations were published in the OECD document (OECD, 2019). The OECD Employment Outlook provides an annual assessment of key labor market developments and prospects in OECD member countries. According to this document:

- Risk of job automation is real but varies greatly across countries. OECD estimates that $14 \%$ of jobs are at high risk of automation - significantly fewer than some researchers have argued Populations are ageing fast in OECD countries. The number of $65+$ year-olds per 100 people of working age is estimated at 53, in 2050 year. In 2015 it was 28 .

- Many adults do not have the right skills for the new job. 6 out of 10 adults lack basic ICT skills or have no computer experience.

- Adult training should better target the disadvantaged.

- Non-standard work is not a marginal phenomenon. 1 in 7 workers is selfemployed and 1 in 9 employees is on a temporary contract.

- Social protection needs to be adapted to the future of work. Non-standard workers are $50 \%$ less likely to be 
unionized and 40-50\% less likely to receive income support when out of work.

The latest OECD results show that around $14 \%$ of jobs are at risk of complete automation but many more will be affected by deep changes. Jobs are at high risk of automation if the likelihood of their job being automated is at least $70 \%$. Jobs at risk of significant change are those with the likelihood of their job being automated estimated at between 50 and $70 \%$.
The following bar graph (Figure 1) shows country-specific estimates. The lower part of the rectangle represents High risk of automation and the upper part Significant risk of change. As many as $33,6 \%$ of jobs in Slovakia are threatened by automation. $30,8 \%$ are significant risk of change. For example, in the Czech Republic, $15,5 \%$ of jobs are at risk. The OECD average is $14,0 \%$. From this comparison, the bad position of the Slovak Republic is obvious.

Figure 1: Jobs at risk of automation in OECD countries

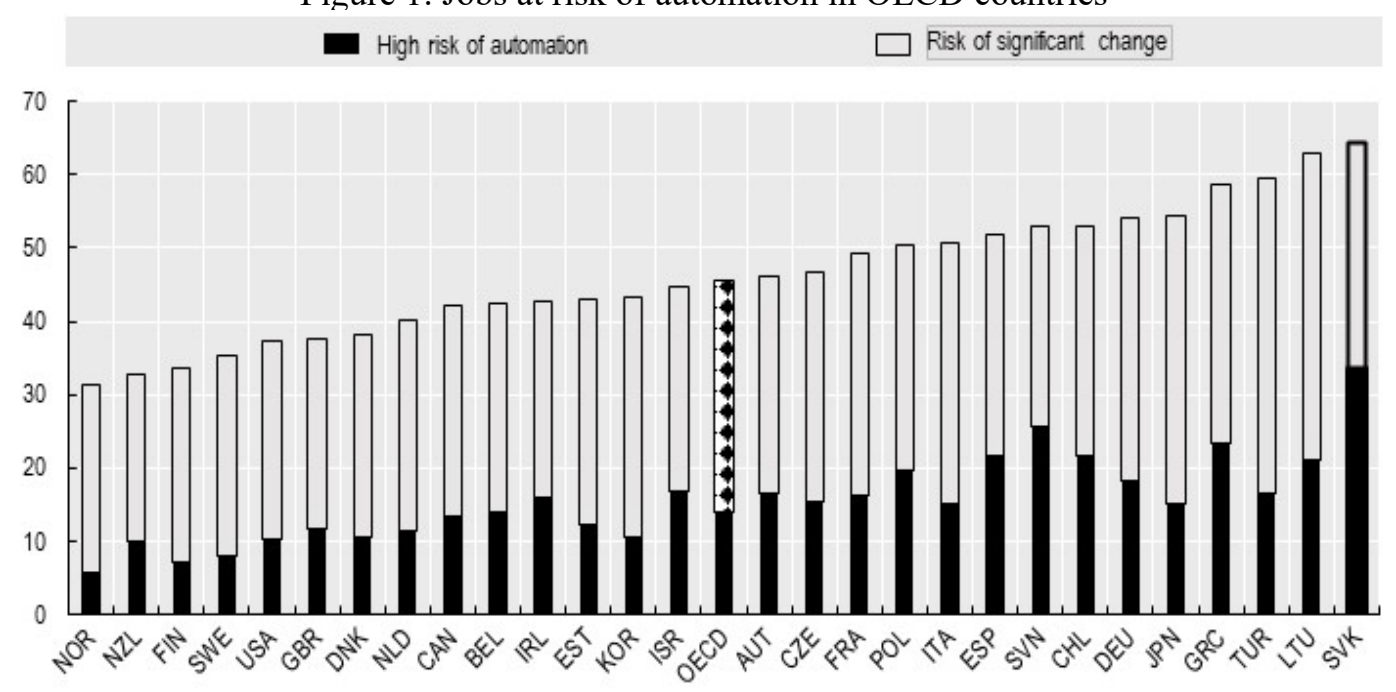

\section{Source: OECD (2019)}

The situation on the labour market in Slovakia will be affected not only by the loss of jobs, but also by their creation. The supply on the labour market will depend on demographic developments, the age of legal entitlement to a pension, remaining in the labour market in retirement age, caring for the family and many other factors. Nevertheless, the decisive factor will be the size of the population in the age of real economic activity of 20-64 years.

In 2019 , economic growth was $4 \%$ due to investment and exports. Thus, imbalances in the labour market in the form of a shortage of skilled labour grew, and unemployment decreased. In 2019, there was an additional need on the labour market for employees in companies of 150,000 people. Cumulatively, the needs of the labour market were almost 190 thousand people. Compared to 2018, the number of self-employed persons decreased. This trend is not new, their number is continuously declining for 10 years. Older people predominate in the age structure of selfemployed persons. At present, the needs of the labor market in the Slovak Republic are dominated by industry and trade. Approximately $36 \%$ of job opportunities in the years 2018-2019 were created in these sectors. The highest share of additional labor needs was in the IT sector.

\section{Regional differences in the labour market}


Regional differences in the labor market result from many factors, such as location, infrastructure, availability of services, concentration of institutions. Labour market flexibility is considered a key factor not only in a country's competitiveness but also within its regions. One of the basic components of labour market flexibility is labour mobility (Eamets and Jaakson, 2014). In general, we distinguish between spatial and job mobility. While spatial mobility is linked to the work of employees, structural mobility reflects the ability of the workforce to move jobs between departments or to adapt to new jobs and skills.

As reported by Niebuhr et al. (2009), labor mobility reinforces regional employment and wage disparities. In the relevant models, the impact of mobility is not only limited to labor supply but is based on the impact on labor demand. According to some models of economic geography (Suedekum, 2004; Epifani, Gancia 2005), due to externalities, migration can lead to widening disparities in regional labor markets. Regional differences in Slovakia are perhaps the most significant in the field of employment. Indicators of economic activity, unemployment, average wage, and the like show a significantly different situation on the labour market in individual Slovak regions.

In practice, the unemployment rate, gross domestic product per capita or average wage are most often used to characterize the labour market. Each of these statistics has its shortcomings. Average wages do not include data on income of self-employed persons, contractual income and the local affiliation of the employee is determined by the seat of the organization. GDP per capita in the regions is hampered by job mobility, official statistics on people's permanent residence or the attribution of the performance of some branches to headquarters in other regions. These indicators are also influenced by the gray economy, which may vary from region to region. Although strong economic growth has led to a significant improvement in the labour market, structural problems persist. (Štefánik et al., 2018)
For this reason, disparities between labour market demand categories (employment, industry) and labour market supply characteristics (education and qualifications achieved) should be closely monitored in the future.

\section{Labour market in the regions of Slovakia}

From a regional point of view, the Bratislava region is the region with the highest need for labor. In the period 2018-2019 it was at the level of 35 thousand people. In the Nitra region 26 thousand, in Banská Bystrica 18 thousand and further in Košice 19 thousand people. As in most developed countries, the labor market trend is moving towards specialists. However, the structure of labor market needs does not converge to the most developed countries. This is due to the significant share of labor market needs in assembly workers. In the Slovak Republic, the structure of labor market needs is thus polarized. High and low qualification of workers is needed. The intermediate qualification is in the background. In 2019, the highest share, approximately $65 \%$, of the expansion in the labor market needs of machine operators was the highest.

Demographic trends and new production processes have a significant impact on the labour market. The population is expected to decline over the long term (by 2035) and will decline the most in regions already struggling with labor shortages (excluding Bratislava). It is also estimated that $33 \%$ of all jobs in Slovakia are highly automated and another $31 \%$ are threatened by a significant change in the way they are implemented (OECD, 2018a). These estimates suggest that almost two-thirds of jobs are at risk, the highest rate among OECD countries. Automation can also help create new jobs. This requires significant investment in adapting to new labour market requirements, which require new and more advanced types of skills and qualifications. Only $33 \%$ of Slovaks currently have higher than basic digital skills. Employers say they have an increasing difficulty finding employees 
with the required skills. The vacancy rate varies considerably from region to region, which has a clear negative correlation with the unemployment rate. Long-term unemployment remains a serious problem. The long-term unemployment rate (as a share of the economically active population) is declining year-on-year, but the average duration of unemployment is among the highest in the EU. Three quarters of the long-term unemployed are concentrated in three regions - Prešov, Košice and Banská Bystrica.

Gender disparities in employment are narrowing, but the employment of women of childbearing age is not improving. For example, the gender employment gap fell by 1,4 percentage points to $12,8 \%$ in 2017 , which is above the EU average. This improvement was mainly due to the higher employment rate of women aged 45+. On the contrary, the employment rate of women aged 25-34 has decreased, which has contributed to a widening gap in this age group. The overall pay gap between women and men is $19 \%$, which is above the EU average (16,2\%) (Štefánik et al., 2018).

\section{THE RESEARCH RESULTS AND DISCUSSION}

Selection of suitable indicators for further analysis is based on database from ILO (2016). For our purposes, the relevant indicators
(Statistical Office of SR), which were officially published at the regional level of Slovakia, NUTS III, were selected. The comparison period was 2010 and 2019. The input indicators are: Economic activity rate (together, university education, secondary education), Average nominal monthly wage (together, industry, university education, secondary education, technicians, operators and fitters), Unemployment rate, Available number of job seekers, Regional gross domestic product per capita. All indicators are calculated per capita in the region. The input data were initially subjected to statistical analysis. Data consistency and multicollinearity were excluded. Normalization of indicators was performed by the Min-Max method. The weight was calculated by individual indicators, using the PCA method. Composite indicator was calculated for each region using a linear aggregation method based on the following formula:

$$
C I_{t}^{r}=\frac{\sum_{i=1}^{n} I_{i}^{T} w_{i}}{\frac{\sum_{1}^{R} \sum_{i=1}^{K} L_{w_{i}}^{T}}{R}}
$$

If the value of the $C I_{t}^{r} \cong 1$, studied region $r$ can be considered as the average. In the case of value greater than 1 for an above average and otherwise mediocre.

The composite indicator takes values around an average of 1 . The higher the value, the better is the assessment of the region. Resulting values $\mathrm{CI}_{t}^{\text {rn }}$ are in the following table:

Table 1: Composite indicator for individual regions

\begin{tabular}{|r|c|c|c|c|c|c|}
\hline $\boldsymbol{r}$ & Region & $\boldsymbol{C I}$ & Ran & $\boldsymbol{C I}$ & Ran & difference \\
\hline 1 & Bratislava & 2,54 & 1 & 2,25 & 1 & $-0,29$ \\
\hline 2 & Trnava & 1,03 & 3 & 0,99 & 3 & $-0,04$ \\
\hline 3 & Trenčín & 0,71 & 6 & 0,88 & 5 & 0,17 \\
\hline 4 & Nitra & 0,80 & 5 & 0,96 & 4 & 0,16 \\
\hline 5 & Žilina & 0,94 & 4 & 1,00 & 2 & 0,06 \\
\hline 6 & Banská & 0,45 & 7 & 0,58 & 7 & 0,13 \\
\hline 7 & Prešov & 0,45 & 8 & 0,47 & 8 & 0,02 \\
\hline 8 & Košice & 1,08 & 2 & 0,87 & 6 & $-0,21$ \\
\hline
\end{tabular}

Source: own computation 
The table shows composite indicator values in 2010 and 2019. In the years under review, the order of the region is also given. The difference is the increase or decrease in the value of the composite indicator. The data are shown in the following

Figure 2: Jobs at risk of automation in OECD countries

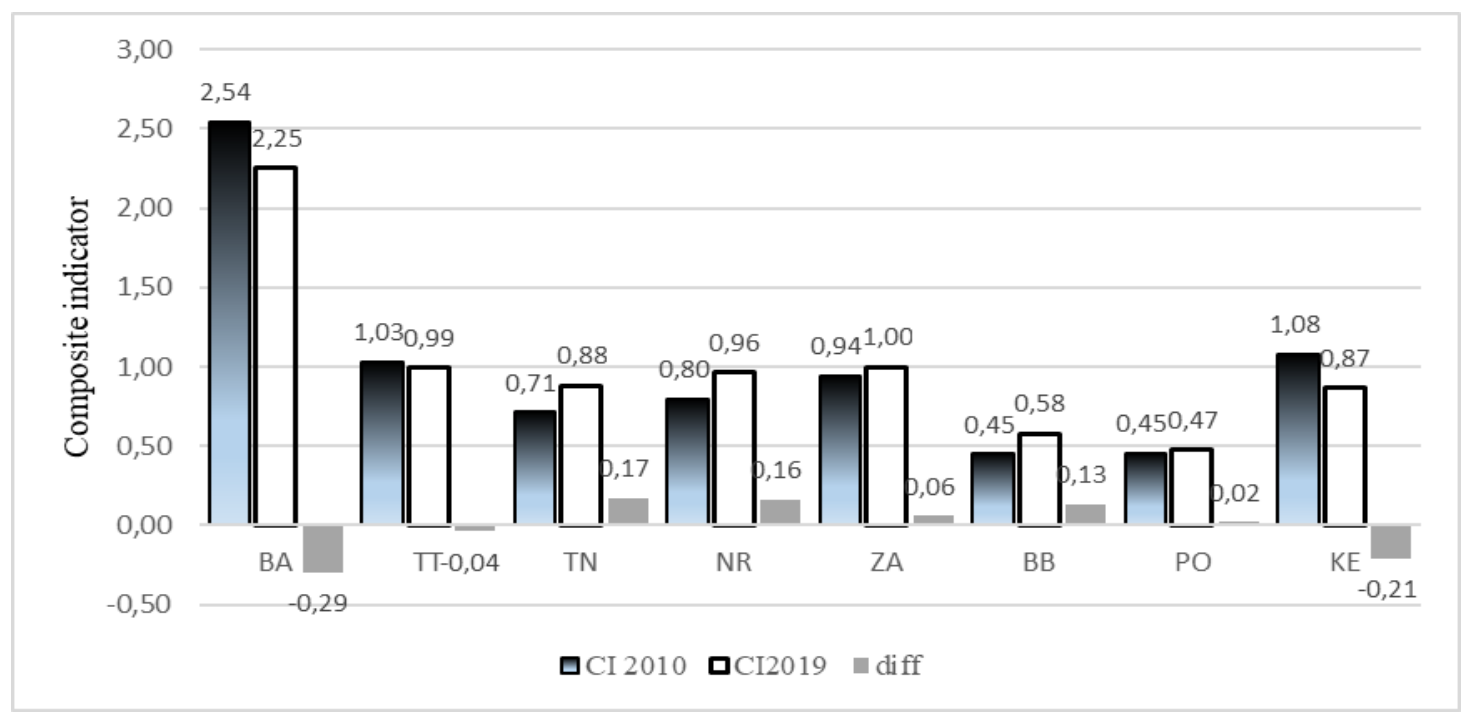

Source: own processing

The Bratislava labour market showed the best potential of the labour market in both years. As mentioned, value $C I_{t}>1$ is characterized by regions as above average. There are values for the Bratislava region $\mathrm{CI}_{2010}$ and $\mathrm{CI}_{2019}$ greater than 2,0, which is highly above average. It decreased by 0,29 during the observed period. Compared to other regions, the number of economically active population with a secondary education has decreased. At the same time, the number of job seekers increased. The $C I$ value also decreased in the observed region in the Košice region, from an average value of 1,08 to a below average 0,87 . A negative change was recorded for most indicators. The biggest positive change in the labour market is recorded in the Trenčín, Nitra and Banská Bystrica regions in the period under review.

\section{Conclusion}

Technological progress automates existing jobs and at the same time introduces new jobs. If automation exceeds job creation, fears of "technological unemployment" will materialize. Technological progress is constantly increasing. There are indications that advances in intelligent technology, robotics, and algorithms, often referred to as the Fourth Industrial Revolution, are proceeding at an unprecedented pace. However, technological revolutions often have a significant impact if they last. It can be stated that in the last ten years, this change has taken place in Slovakia. It significantly affects the change in the labour market. However, the last period is marked by an unpredictable situation due to the pandemic. The COVID-19 pandemic has caused the worst economic recession since World War II, causing enormous damage to people's health, jobs, and well-being. The Slovak economy is expected to show a decline of $6 \%$ in 2020. A pandemic could lead to lasting changes in demand and structural shifts in the economy. Total employment should fall by $2,1 \%$. Well- 
targeted labour market activation policies should be linked to a strong social safety net to alleviate the necessary costs of adjustment when moving to new jobs.

Changes of key labour market indicators in Slovakia in recent years are mapped. The analysis is performed using a constructed composite indicator. The composite indicator includes officially published key labor market indicators in the regions. The results of the analysis indicate changes in the labour market.

\section{References}

Berger, R. (2016). Skill Development for Industry 4.0. BRICS Business Council. India edition.

Eamets, R., Jaakson, K. (2014). Labour market flexibility and spatial mobility. International Journal of Manpower. Vol. 35. No. 6, pp. $746-752$.

Epifani, P., Gancia, G. A. (2005). Trade, migration and regional unemployment. Regional Science and Urban Economics. Vol. 35, pp. $625-644$.

Havierniková, K., Král'ová, K. (2019) Analysis of selected issues related to human resources and Industry 4.0 in case of engagement into cluster cooperation on example to technological SME. The impact of Industry 4.0 on job creation. Trenčín: TnUAD, 81-88.

Hoellthaler, G., Braunreuther, S., Reinhart, G. (2018). Digital Lean Production. An Approach to Identify Potentials for the Migration to a Digitalized Production System in SMEs from a Lean Perspective. Procedia CIRP, 67, 522-527. [online]. [acc.2021-02-2]. Retrieved from: https://doi.org/10.1016/J.PROCIR.2017.1 2.255
A positive change was registered in the Trenčín, Nitra and Banská Bystrica regions. It is difficult to assess how these changes are related to technological changes in the regions. To do this, it would be necessary to analyze the impact of several input factors on the output factors. It would also be appropriate to compare the results with other methods of labour market analysis in the regions. However, it can be stated that regional disparities decreased during the period under review. This fact should also be statistically verified in a broader context.

ILO (2016). Key Indicators of the Labour Market, Ninth edition. Geneva, International Labour Office. Retrieved from: https://www.ilo.org

Minařík, K., Borůvková, J., Vystrčil, M. (2013). Analýzy v regionálním rozvoji. Professional Publishing, Př́bram

Nardo M., Saisana M., Saltelli A., Tarantola S., Hoffman A., Giovannini E. (2005). Handbook on constructing composite indicators: methodology and user guide. OECD Statistics Working Paper, Paris

Neufeind, M., O'Reilly, J., Ranft, F. (2018). Work in the digital age. Challenges of the Fourth Industrial Revolution. Rowman \& Littlefield International Ltd. Policy Network, London

Niebuhr, A., Granato, N., Haas, A., Hamann, S. (2009). Does labour mobility reduce disparities between regional labour markets in Germany? IAB -Discussion Paper 15/2009. Nuremberg: Institute for Employment Research of the Federal Employment Agency.

OECD (2018a), OECD Regulatory Policy Outlook 2018. OECD Publishing, Paris. Retrieved from: https://www.oecd.org/governance/oecdregulatory-policy-outlook-20189789264303072-en.htm 
OECD (2019). OECD Employment Outlook 2019: The Future of Work. OECD Publishing, Paris. Retrieved from: https://doi.org/10.1787/9ee00155-en

Saisana M., Tarantola, S. (2002). State-ofthe-art report on current methodologies and practices for composite indicator development, EUR 20408 EN, European Commission-JRC: Italy

Suedekum, J. (2004). Increasing returns and spatial unemployment disparities. Papers in Regional Science, Vollume 84 isssue 2, pp. $159-181$

Schwab, K. (2015). The Fourth Industrial Revolution: What It Means and How to Respond. Retrieved from https://www.foreignaffairs.com/articles/2 015-12-12/fourth-industrial-revolution.

Štefánik, M. [et al.] (2018). Labour market in Slovakia 2019+. ŠEVT, Bratislava 2018.

\section{Contact}

RNDr. Dana Jašková, PhD.,

Department of Economics and Economics Faculty of Social and Economic Relations Alexander Dubček University in Trenčín Študentská 3, 91150 Trenčín, dana.jaskova@tnuni.sk
Vuksannovič, D., Ugarak, J., Korčok, D. (2016). Industry 4.0: The future concepts and new visions of factory of the future development. International scientific conference on ICT and e.business related research, SINTEZA, pp. $293-298$.

$\mathrm{Xu}, \mathrm{M}$. [et al.]. (2018) The Fourth Industrial Revolution: Opportunities and Challenges. International Journal of Financial Research Vol. 9, No. 2. Retrieved from: http://ijfr.sciedupress.com

DataCube (2021). Statistics [online]. [cit.2021-03-01]. Available at: http://datacube.statistics.sk.

https://www.trendyprace.sk/sk/trendy-trhuprace/sk-trendy/slovensko 